\title{
Aortic Valve Regurgitant Jet Width
}

National Cancer Institute

\section{Source}

National Cancer Institute. Aortic Valve Regurgitant Jet Width. NCI Thesaurus. Code C127541.

The measured width of the backflow of blood into the left ventricular outflow tract. 